\title{
Report on Non-fatal events cardio-cerebro-vascular to ten years in a Southern Italy cohort
}

\section{Eventi cardio-cerebro-vascolari non fatali, in un periodo di dieci anni, in una coorte del Sud Italia}

\author{
Vincenzo Capuano, Norman Lamaida, Rocco Capuano, \\ Eduardo Capuano, Sergio Torre, Federica Marchese, Ernesto Capuano
}

\begin{abstract}
Report on Non-fatal events cardio-cerebrovascular to ten years in a Southern Italy cohort. V. Capuano, N. Lamaida, R. Capuano, E. Capuano, S. Torre, F. Marchese, E. Capuano.

Background: Data relating to non-fatal cardiovascular events are poor but these data are essential to organize targeted interventions on the territory and to understand their effectiveness.

Methods: We calculated the rates of morbidity from cardiovascular events covering the period 1998/99 - 2008/09, in a cohort of 1200 persons (600 men and 600 women) aged 25 to 74 years. Data were standardized using the European standard population.

Results: The incidence of events to ten years of nonfatal myocardial infarction was $2,2 \%$ in men and of $1,8 \%$ in women. PCI interventions to ten year have been $3,3 \%$ in men and $3,4 \%$ in women, the interventions of aorto-coro-
\end{abstract}

nary bypass have been $2,4 \%$ and $0,5 \%$ for men and women respectively. While all major cardiovascular events have been more frequent in men, in women there was a higher incidence of stroke $(1,6 \%$ vs $0,9 \%)$.

Conclusion: Although by comparison with other European countries Italy is among the countries considered at low-risk of coronary heart disease, in Campania cardiovascular diseases reach higher rates than the rest of the country. Our results are in keeping with the literature data and confirm that cardiovascular diseases are a major public health problem. Local analysis are useful in providing additional information for planning prevention interventions targeted to its own territory. Project.

Keywords: cardiovascular mortality, Southern Italy, Vip

Monaldi Arch Chest Dis 2014; 82: 183-186.

Operative Unit of Cardiology and UTIC - Mercato S. Severino Hospital, University Hospital of Salerno - Italy.

Corresponding author: Vincenzo Capuano, MD, Operative Unit of Cardiology and UTIC - Mercato S. Severino Hospital, University Hospital of Salerno; Via R. Livatino, 30; I-84080 Pellezzano (SA), Italy; Tel. 089-9925246; Fax 089-879634; E-mail address: capuanov@tiscali.it

\section{Introduction}

The analysis of local epidemiological data enables to design prevention interventions targeted at the studied area and to assess the impact over time. In Italy prevention interventions are poor and, as well as throughout Europe, large segment of the population has uncontrolled cardiovascular risk factors and does not adopt appropriate lifestyles [1].

Further studies are therefore indispensable for planning interventions to prevent cardiovascular involving the broad population.

Epidemiological data are essential for planning and evaluating prevention interventions targeted to the territory. Numerous studies have analyzed the mortality rates and the prevalence of classic cardiovascular risk factors. On the contrary prospective data relating to non-fatal cardiovascular events are poor [2].

This work, which was established under a project on epidemiology and primary prevention of cardiovascular diseases, would help to know the incidence of cardio-cerebro-vascular events in a Mediterranean area.

\section{Methods}

Data were collected as part of Project VIP (Valle dell'Irno Prevenzione), a project of epidemiology and primary prevention of cardiovascular diseases, in the province of Salerno [3-5]. The VIP project is part of the CINDI Program [6, 7] of the World Health Organization. In the years 1998/99 study has involved the creation of the baseline through cross-sectional survey, in which they were collected physiological parameters related to a cohort of 1200 men and women aged between 25 and 74 years [3]. Only $3.3 \%$ of men and $0.2 \%$ of women reported a previous myocardial infarction and $0.7 \%$ of men and women reported a previous stroke. The cross-survey was conducted across a sample of people randomly chosen from the population of residents of the towns of Baronissi and Mercato S. Severino, examined by standardized methods recommended by the MONICA Project and the Observatory Cardiovascular Epidemiology [8-9].

Ten years later (2008-09) life status of all participants was monitored through the municipality of 
residence and the people were contacted by letter or telephone or through primary care physicians. The collected data were matched with deterministic method (full name, date of birth, telephone number), with hospital discharge records and RENCAM cards, made available by service expertise. In this way we have obtained information on health status and any deaths of 1175 of 1200 people visited in the period 1998-99: 587 men and 588 women. The sample size was slightly reduced compared to the initial sample. The events considered were concerning cardiovascular morbidity (ICD10: $120-125$ and 160-169). In this study we consider and describe the incidence of non-fatal events: Cardiovascular events (CVE). Events were grouped into: myocardial infarction (AMI), angina, stroke, coronary artery bypass graft $(\mathrm{CABG})$, percutaneous coronary intervention (PCI), transient ischemic attack (TIA), percutaneous transluminal angioplasty (PTA) or carotid endoarterectomy, aortic aneurysmectomy.

The events considered were those for which there was documentation (medical record or medical report).

The data have been retrieved from:

- Medical records found at the referral hospital;

- Documentation provided by general practitioner;

- Documentation provided by patient (medical records of other hospital and / or medical report).

We have obtained the overall number of people affected by events, the number of deaths, the number of subjects with non-fatal cardiovascular events and the number of subjects with non-cardiac vascular events, but at the same time the frequency of cardiovascular events and revascularization procedures in the following way:
1) we have identified 86 (62 men and 24 women) fatal events;

2) in people in life (525 men and 564 women) we have detected non-fatal cardiovascular events and identified subjects who reported at least one event.

Finally, we have calculated the incidence rates, standardized using a direct method considering the European standard population as reference.

Incidence of events is reported as $\mathrm{N}^{\circ}$ events / 100 people for a period of 10 years.

\section{Results}

Mortality data (Figure 1) are reported in a previous article [10]. The CVE recorded in 10 years were 126 (71 men and 55 women). It should be noted that non-fatal cardiovascular events were already being recorded in the youngest age group (2534 years). The non-fatal events were more frequent than with mortality, with the exception of men aged 65-74 years where, instead, deaths are more frequent. The incidence of CVE is show in Table 1 and Table 2. In the older group myocardial infarctions occurred in $3.5 \%$ of women and $3.4 \%$ of men over 10 years. The interventions of PTCA, in 10 years, were amounting to $3.3 \%$ in men and $3.4 \%$ in women, with a different frequency for the age: higher among younger age groups in men, higher in the older age groups in women. The CABG were less frequent: $2.4 \%$ in men and $0.5 \%$ in women. Major cardiovascular events were more frequent in men with the exception of stroke, which were detected more frequently in women $(1.6 \%$ vs $0.9 \%$; $\mathrm{P}$ value $=0.01)$.

Table 1. - Incidence of major cardiovascular events at 10 years

\begin{tabular}{|c|c|c|c|c|c|c|c|c|c|c|c|c|c|c|c|c|c|}
\hline \multicolumn{9}{|c|}{ Men } & \multicolumn{9}{|c|}{ Women } \\
\hline & \multicolumn{2}{|c|}{ AMI } & \multicolumn{2}{|c|}{ Stroke } & \multicolumn{2}{|c|}{ CABG } & \multicolumn{2}{|c|}{ PCI } & & \multicolumn{2}{|c|}{ AMI } & \multicolumn{2}{|c|}{ Stroke } & \multicolumn{2}{|c|}{ CABG } & \multicolumn{2}{|c|}{ PCI } \\
\hline & $\mathrm{N}^{\circ}$ & $\%$ & $\mathrm{~N}^{\circ}$ & $\%$ & $\mathrm{~N}^{\circ}$ & $\%$ & $\mathrm{~N}^{\circ}$ & $\%$ & & $\mathrm{~N}^{\circ}$ & $\%$ & $\mathrm{~N}^{\circ}$ & $\%$ & $\mathrm{~N}^{\circ}$ & $\%$ & $\mathrm{~N}^{\circ}$ & $\%$ \\
\hline $\begin{array}{l}25 \text { - } 44 \text { years } \\
235 \text { Subjects }\end{array}$ & 2 & 0.9 & 0 & $\mathbf{0}$ & 1 & 0.4 & 1 & 0.4 & $\begin{array}{l}25-44 \text { years } \\
238 \text { Subjects }\end{array}$ & 1 & 0.4 & 1 & 0.4 & 0 & 0 & 2 & 0.8 \\
\hline $\begin{array}{l}45 \text { - } 54 \text { years } \\
118 \text { Subjects }\end{array}$ & 4 & 3.4 & 1 & 0.8 & 2 & 1.7 & 8 & 6.8 & $\begin{array}{l}45-54 \text { years } \\
120 \text { Subjects }\end{array}$ & 3 & 2.5 & 2 & 1.7 & 1 & 0.8 & 2 & 1.7 \\
\hline $\begin{array}{l}55 \text { - } 64 \text { years } \\
118 \text { Subjects }\end{array}$ & 4 & 3.4 & 2 & 1.7 & 9 & 7.6 & 7 & 5.9 & $\begin{array}{l}55 \text { - } 64 \text { years } \\
116 \text { Subjects }\end{array}$ & 4 & 3.4 & 4 & 3.4 & 1 & 0.8 & 10 & 8.6 \\
\hline $\begin{array}{l}65-74 \text { years } \\
116 \text { Subjects }\end{array}$ & 4 & 3.4 & 4 & 3.4 & 4 & 3.4 & 4 & 3.4 & $\begin{array}{l}65-74 \text { years } \\
114 \text { Subjects }\end{array}$ & 4 & 3.5 & 4 & 3.5 & 2 & 1.7 & 10 & 8.8 \\
\hline $\begin{array}{c}\text { Crude rate } \\
587 \text { Subjects }\end{array}$ & 14 & 2.4 & 7 & 1.2 & 16 & 2.7 & 20 & 3.4 & $\begin{array}{l}\text { Crude rate } \\
588 \text { Subjects }\end{array}$ & 12 & 2 & 11 & 1.9 & 4 & 0.7 & 24 & 4.1 \\
\hline $\begin{array}{l}\text { Standardized } \\
\text { rate* }\end{array}$ & & 2.2 & & 0.9 & & 2.4 & & 3.3 & $\begin{array}{l}\text { Standardized } \\
\text { rate* }\end{array}$ & & 1.8 & & 1.6 & & 0.5 & & 3.4 \\
\hline
\end{tabular}


Table 2. - Cardiovascular events in ten years, expressed as a percentage, in both sexes. Standardized data with the European population as reference

\begin{tabular}{cccc}
\hline Events & Men & Women & P value \\
\hline cardiovascular mortality & $3,6 \%$ & $1,4 \%$ & 0.01 \\
\hline AMI & $2,2 \%$ & $1,8 \%$ & NS \\
\hline Angina & $0,7 \%$ & $0,2 \%$ & NS \\
\hline CABG & $2,4 \%$ & $0,5 \%$ & 0.01 \\
\hline PTCA & $3,3 \%$ & $3,4 \%$ & NS \\
\hline Stroke & $0,9 \%$ & $1,6 \%$ & 0.47 \\
\hline TIA & $1,3 \%$ & $0,2 \%$ & 0.44 \\
\hline PTA carotid & $0,6 \%$ & $0,4 \%$ & NS
\end{tabular}

\section{$\square$ Cardiovasc}

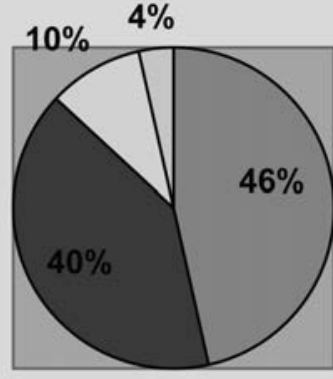

Men

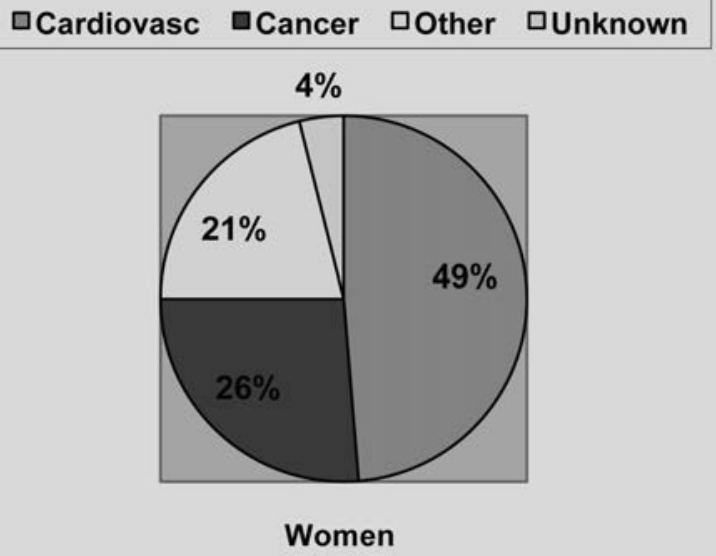

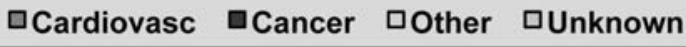

Women

Figure 1. - Percentage distribution of causes of mortality - Men and Women Standardized data with the European population as reference.

\section{Discussion}

The cardio-cerebro-vascular diseases in the Campania region are among the most of the Mediterranean and the high incidence of non-fatal cardiovascular events recorded in our work confirm this result. These data are consequence of the high prevalence of cardiovascular risk factors in the population, showed also from data of the Cardiovascular Epidemiology Observatory [9], collected in the same year in which we have enrolled our cohort in the study (part of the data collected in Campania belongs to the same territory). These data show that all risk factors considered have a higher prevalence in Campania than the Italian average: 6 of 6 in women and in 4 of 6 men (Table 3). In Campania the province of Salerno presents a standardized mortality rate, for the years 90-94, slightly lower than the regional one, but still higher than the Italian one, especially for women [11]. A survey in our area, in the early 90 s showed a mortality rate from cardiovascular disease of $50 \%$ of the general one [12].

The morbidity data are more difficult to compare because, in Europe, there is no systematic collection relating to non-fatal cardiovascular events [2]. There are few prospectively collected data, such as in our study. For this reason our data offer a more complete view of the problem. The most important aspects to highlight are:

- Events increase with age;

- In women the incidence of cardiovascular events increases with age to reach the highest values in the older group, while in men the incidence is greatest in the decade 55-64 years of age, to be reduced in the next, where cardiovascular mortality becomes rather higher;

- The incidence of nonfatal myocardial infarction is similar in both men and women in the age group $65-74$ years $(3.5 \%)$;

- The procedures of myocardial revascularization (CABG and PTCA) are particularly frequent in both sexes and all ages, attaining the highest in men between 55 and 64 (13.5\% in 10 years) and in women between 65 and 74 years $(10.5 \%)$. The higher number of revascularizations in men is probably the consequence of a lower level of coronary atherosclerosis in women, but probably a minor medical attention for women;

- Major cardiovascular events are more frequent in men with the exception of strokes, which are more frequent in women. This phenomenon has been shown in other studies about Campania population and it is likely a result of the high prevalence of hypertension and obesity in women in Campania [13]. 
Table 3. - Prevalence of major cardiovascular risk factors in Italy and in Campania (age 35-74 years). Cardiovascular Epidemiology Centre data - year 1998 (9).

\begin{tabular}{ccccccc}
\hline & \multicolumn{3}{c}{ Men } & \multicolumn{2}{c}{ Women } \\
\hline & Italy & Campania & P value & Italy & Campania & P value \\
\hline Hypertension & $33 \%$ & $29 \%$ & $<0.01$ & $28 \%$ & $33 \%$ & $<0.01$ \\
\hline Hypercholesterolemia & $21 \%$ & $19 \%$ & $<0.05$ & $23 \%$ & $27 \%$ & $<0.01$ \\
\hline Smokers & $33 \%$ & $41 \%$ & $<0.01$ & $23 \%$ & $25 \%$ & $<0.05$ \\
\hline Sedentary & $34 \%$ & $35 \%$ & $\mathrm{NS}$ & $46 \%$ & $52 \%$ & $<0.01$ \\
\hline Diabetes & $10 \%$ & $11 \%$ & $\mathrm{NS}$ & $7 \%$ & $8 \%$ & $\mathrm{NS}$ \\
\hline Obesity & $17 \%$ & $18 \%$ & $\mathrm{NS}$ & $21 \%$ & $33 \%$ & $<0.01$ \\
\hline
\end{tabular}

In conclusion we confirm that cardiovascular disease with their high incidence of mortality and morbidity are major public health problem, as they need high spending care, often leading to premature disability and resulting in a significant emotional burden on patients and families. The levels of incidence and mortality of cardiovascular events highlighted in this study in an area of Campania region concern because cardiovascular disease is predictable. Acting on the main risk factors, that are widely known, it is possible to reduce the risk: there are clear demonstrations of a low incidence of cardiovascular events in populations at low risk [14]. The data on the elderly population are very interesting: in this age group the incidence of events reaches levels that need to reflect upon why they are probably the consequence of a further decline in attention toward preventive measures.

Furthermore, an analysis of avoidable mortality from ischemic heart disease with primary prevention interventions [15] shows how the Campania is the region with the largest number of preventable deaths for both sexes: $62.5 \%$ of cases in men (Italy $48.5 \%$ ) and $21.2 \%$ of cases in women $(13.8 \%$ in Italy) could be avoided.

This shows how the implementation of prospective studies, the collection and analysis of epidemiological data acquire significance only if the information obtained will be used by the clinic to continue to build cardiovascular prevention programs targeted to the area studied. For this purpose, it becomes increasingly necessary to raise awareness of clinical cardiologists to consider the epidemiological data among the tools necessary to optimize their strategies for intervention in the population. This intervention is even more important if it is lowered into the reality of reference.

The aim is to promote dialogue among clinical cardiologists, primary care physician and practitioners of prevention through the discussion of data like this our study.

\section{References}

1. Banegas JR, López-García E, Dallongeville J, Guallar E, Halcox JP, Borghi C, Massó-González EL, Jiménez FJ, Perk J, Steg PG, De Backer G, Rodríguez-Artalejo F. Achievement of treatment goals for primary prevention of cardiovascular disease in clinical practice across Europe: the EURIKA study. Eur Heart J 2011; 32: 2143-2152.
2. Melanie Nichols, Nick Townsend, Peter Scarborough and Mike Rayner. European Cardiovascular Disease Statistics 2012 Edition.

3. Capuano V, D'Arminio T, Bambacaro A, Lanzara C, D'Antonio V. Il Progetto VIP prevalenza dei fattori di rischio della cardiopatia ischemica in un'area della Campania. Ital Heart J Suppl 2001; 2 (11): 1201-1208.

4. Capuano V, Bambacaro A, D'Arminio T, Del Regno B, D'Antonio V, Lanzara C. Changes in total serum cholesterol for cardiovascular disease in a Mediterranean area, 19891999. European Journal of Epidemiology 2002, 18: 27-32.

5. Capuano V, D'Armino T, La Sala G, Mazzotta G. The third component of the complement (C3) is a marker of the risk of atherogenesis. European Journal of Cardiovascular Prevention \& Rehabilitation 2006; 13: 658-60.

6. CINDI Programme-Protocol and Guidelines-WHO Regional Office for Europe, Copenhagen, 1996.

7. Tenconi MT, Gianti A, Carreri V, Capuano V, Dormi A, Giampaoli S, Muntoni S, Vanuzzo D. Il Programma CINDI dell'OMS e la partecipazione italiana. Igiene e Sanità Pubblica 2000; 6: 505-16.

8. Menotti A, Giampaoli S, Verdecchia A, Cesana GC, Feruglio GA, Righetti G, Ferrario M, and Vanuzzo D. Il Progetto MONICA (monitoraggio malattie cardiovascolari). Protocollo e manuale delle aree italiane. Roma rapporti Istisan/ISTISAN 89/12, 1989.

9. Giampaoli S, Vanuzzo D, e il Gruppo di Ricerca dell'Osservatorio Epidemiologico Cardiovascolare. I fattori di rischio cardiovascolare in Italia: una lettura in riferimento al Piano Sanitario Nazionale 1998-2000. G Ital Cardiol 1999; 29: 1463-1471

10. Capuano V, Lamaida N, Torre S, Capuano E, Borrelli MI, Capuano E, Clarizia MM, Capuano R, De Rosa C. Ten year cardio-cerebro-vascular mortality and morbidity in a Southern Italy cohort: the VIP project data. Monaldi Arch Chest Dis 2013; 80 (1): 31-34

11. De Girolamo G, Feola G, Donato A. La mortalità per cause in provincia di Salerno. Amministrazione Provinciale di Salerno. 2000.

12. Servizio informazioni e pubbliche relazioni ASL 47. Le cause di morte nell'USL 47. Salerno Tipografia Iannone 1993: $1-40$

13. Minelli G, Manno V, D'Ottavi SM, Masocco M, Rago G, Vichi M, Crialesi M, Frova L, Demaria M, Conti S. La mortalità in Italia nell'anno 2007. Roma: Istituto Superiore di sanità; 2010. (Rapporti ISTISA 10/27).

14. Palmieri L, Donfrancesco C, Giampaoli S, Trojani M, Panico S, Vanuzzo D, Pilotto L, Cesana G, Ferrario M, Chiodini P, Sega R, Stamler J. Favorable cardiovascular risk profile and 10 year coronary heart disease incidence in women and men: results from the Progetto Cuore. European Journal of Cardiovascular Prevention \& Rehabilitation 2006; 13: 562-570.

15. Buzzi N, Cananzi G, Conti S, Crialesi R, Lispi L, Panà A. Atlante ERA per La mortalità evitabile 2007. Roma Agenzia D. 2007: 1-300. 